Género, comunicación e investigación desarrollada por mujeres

Gender, communication and women's research

\title{
Michèle Mattelart
}

Resumen

El texto propone una reflexión sobre la diversidad de enfoques en los estudios de género y su impacto renovador en las problemáticas de la comunicación (desde la sociología funcionalista de origen norteamericano, el pensamiento crítico de la Escuela de Fráncfort, el movimiento estructuralista francés, o los Cultural Studies británicos) a través del hilo conductor de las vivencias personales y los trabajos de investigación académica de la autora desarrollados en Francia y en Chile. Producto de esta experiencia se reivindica la importancia política de la representación del género en las sociedades contemporáneas y cómo ésta se utiliza para articular las reglas de las relaciones sociales y para constituir el sentido de la experiencia.

Palabras clave

Estudios de género, estudios feministas, comunicación, representación. 
El tema de género, comunicación e investigación desarrollada por mujeres nos invita en primer lugar a un ensayo de síntesis y una puesta en perspectiva de los estudios sobre Género y Comunicación, desde nuestra propia experiencia de investigación, lo que tiene sus dificultades, dado el tiempo de exposición del que disponemos.

Comenzaré indicando algunos puntos que ayuden a entender los primeros pasos de mi trayectoria. Se trata de dos espacios geográficos. Por un lado está Francia, donde nací y estudié «Literatura Comparada» en una Universidad donde el movimiento estudiantil militaba contra la guerra colonial de Argelia. Por otro lado está América Latina, Chile específicamente. Además esos primeros pasos se dieron en un momento histórico determinante: mitad de los años sesenta y años setenta, cuando, todavía, la disciplina de la Comunicación no se había constituido como tal en la institución académica y el Feminismo se construía como el movimiento que conocemos hoy con su diversidad de fases y enfoques según los contextos nacionales, las sensibilidades políticas y los acercamientos heurísticos.

Me conformaré con subrayar, de entrada, la interacción entre los dos dominios que nos ocupan hoy y con decir que las investigaciones feministas han tenido un impacto renovador sobre las problemáticas de la comunicación. A pesar de eso, como bien se ha señalado en varias oportunidades, la cuestión tanto como se enunció en sus inicios («Mujeres y Medios»), tal como ahora se enuncia («Género y Comunicación» y la diferencia es significativa) sigue ocupando un lugar marginal en la Academia. Todas las antologías que se publican sobre esta problemática lo subrayan. Eso vale para el país de donde vengo, Francia, y también para España, según, al menos, las afirmaciones de las investigadoras de esta región. Sin embargo, todas ellas son firmes en reconocer y valorar la vocación política de sus investigaciones, que parten de la relación permanente entre teoría y práctica y de su defensa de la crítica y de la transformación social. He hablado de dos lugares. Como saben seguramente algunos/as de ustedes, mis investigaciones sobre el tema empezaron en Chile donde viví unos diez años entre 1963 y 1973. Reconozco que buena parte de los avances en el plano teórico que tuvieron influencia en la aproximación al tema «Mujeres/Medios», se los debo a la historia social y política de este país y, particularmente, a mi participación activa en un periodo clave de su historia, a mi compromiso al lado de los sectores que impulsaron un cambio democrático.

Chile categorizado entonces como «país en vías de desarrollo» me puso frente a cuestiones vinculadas con las relaciones Norte/Sur que fueron cruciales en los decenios 60/70. Por ejemplo, con la orientación sobre las políticas de desarrollo guiadas por las doctrinas del «difusionismo», es decir, por la idea unilateral de una modernidad interpretada como la expresión de la superioridad de la civilización occidental ${ }^{1}$.

Este aspecto de mi experiencia motivó mi sensibilización sobre los problemas de la convivencia internacional, en relación a cómo las mujeres se ven afectadas por esa "ideología de la modernidad" que sigue impregnando, aún hoy, una visión del mundo que marca, en muchos de sus aspectos, las políticas nacionales e internacionales de la inmigración, de los intercambios culturales, etc. Las numerosas ONG que trabajan sobre el tema "Mujeres y Desarrollo" se hallan confrontadas a diario a estas formas de pensar, por ejemplo, el tema del "pañuelo", o del "velo", expresión de la reivindicación identitaria de las jóvenes estudiantes musulmanes que fue objeto de tanto debate en Francia y en algunos otros países de Europa, revela la vigencia de ese concepto occidentalista de modernidad para valorar el pasaje del "tradicionalismo" a la "emancipación"; vigencia que analizan, hoy en día, las investigadoras feministas que se adhieren a la corriente de los estudios post-coloniales

Dos de mis primeros estudios supusieron un acercamiento a medios presentados como vectores de un proyecto particular de modernidad: los magazines femeninos divulgados en Chile. Tanto los foráneos, como los nacionales, entraban en esta categoría. Publicados sea por empresas transnacionales, sea por las clases que a nivel local son compatibles con las capas dominantes de los países del centro, promovían modelos de vida y de consumo definidos por las aspiraciones de estos sectores. Esta dinámica ha permanecido y se ha generalizado e incrementado hasta hoy, casándose con las innovaciones perpetuas de la moda, difundida desde los polos hegemónicos que en repetidas ocaciones buscan su inspiración en ¡la originalidad de los subalternos!

La sociología funcionalista de origen norte-americano -a la que recurrían los/las sociólogos/as del desarrollo que acabo de evocarconsideraba los medios de comunicación como nuevos instrumentos de la democracia moderna, como mecanismos decisivos de reproducción de los valores del sistema social existente.

Por el contrario, desde las escuelas de pensamiento crítico que van a reflexionar sobre ellos, los medios de comunicación resultan sospechosos de violencia simbólica y serán analizados como medios de poder y de dominación. Desde los años 40 , los filosofos de la Escuela de Fráncfort, exiliados en los Estados Unidos a causa de la subida al poder de Hitler en Alemania e inspirados por un marxismo en ruptura con la ortodoxia, se inquietan por el devenir de la cultura. Veinte años más tarde, el movimiento estructuralista, nacido en Francia,

\begin{abstract}
${ }^{1}$ El primer estudio que hice en Chile, con Armand Mattelart, tuvo como propósito recoger las opiniones y actitudes de las mujeres de las clases populares frente a las campañas de « control de la natalidad », impulsadas por fundaciones norte-americanas en colaboración con organismos públicos nacionales en el marco de la Alianza para el Progreso, que era el plan de ayuda imaginado por las agencias de los Estados Unidos para contrarrestar la influencia de la revolución cubana en el continente . (La sobrepoblación estaba presentada en estos años por los expertos internacionales en desarrollo como uno de los factores que obstaculizaban el desarrollo de América Latina). Estas campañas recurrían a los medios con la lógica del marketing, utilizando a famosas actrices hollywoodenses con el fin de motivar a las mujeres chilenas a adoptar un comportamiento conforme a la actitud « moderna ». La mujer estaba concebida como una cliente y no como una persona confrontada a su maternidad, su pareja, su familia, su cuerpo. Estas políticas participaban de lo que se ha llamado « el difusionismo » : la propagación de los modelos modernos de comportamiento desde la cultura de los países occidentales. El progreso era interpretado como la difusión de los modelos del Centro hacia los países de la periferia.
\end{abstract}

Armand Mattelart (asi empezó nuestra colaboración) que llegó a Chile como demógrafo y yo, como ciudadana consciente de la violencia simbólica que esto involucraba, decidimos recoger las actitudes de las mujeres, sus respuestas a estas formas de concebir la regulación de los nacimientos y opusimos un método de encuesta de corte antropológico, que ubicaba a la mujer como sujeto. Esta fue mi primera aproximación a la relación medios, interculturalidad y mujer. Este estudio fue publicado bajo el titulo La Mujer chilena en una nueva sociedad, Un estudio exploratorio acerca de la situación e imagen de la mujer en Chile (Santiago, Editorial del Pacifico, 1968). 
opone al método empirista el redescubrimiento de la ideología. En Gran Bretana, en esos mismos años sesenta, el grupo de Birmingham inaugura los Cultural Studies.

Los conceptos-clave que contribuyeron en esos años setenta a construir la tradición francesa del análisis del discurso son los que gravitan en torno al redescubrimiento de "la ideología", basados sobre el pensamiento del filosofo marxista Louis Althusser, del semiólogo Roland Barthes y del sicoanalista Jacques Lacan. Una fuente de inspiración determinante para el análisis del discurso fue la noción de mito, elaborada por Barthes en su obra Mythologies(1957). Algunas palabras caracterizan la función del mito y de sus estrategias discursivas: el mito "naturaliza" el mundo social y sus disparidades ; el mito "recupera" los aspectos subversivos de los movimientos de emancipación. Este enfoque estructural del análisis de los discursos ofrecía una alternativa a la estrechez de los análisis de contenido de la sociología funcionalista americana asumida como la descripción objetiva, sistemática y cuantitativa del contenido manifiesto de las comunicaciones. El aporte decisivo del estructuralismo fue precisamente el de buscar el sentido del proceso de comunicación en el nivel latente 0 subyacente de los discursos.

Desde los primeros años setenta, este enfoque, centrado sobre el papel de la dimensión ideológica en la reproducción y cohesión social, despuntó en los círculos de investigación critica en Ciencias Sociales en América Latina como en el resto del mundo.

Mis estudios sobre dos géneros de cultura popular/ de masas destinados a la clientela femenina (fotonovelas y revista femenina ilustrada) van a recurrir a dicho enfoque del análisis del discurso. Uno tercero, realizado en Francia, después de mi expulsión de Chile por la Junta Militar a finales de 1973, consistió en un análisis sobre el comportamiento de dichas revistas afiliadas a los sectores de la derecha chilena cuando ésta, en su estrategia de oposición al Presidente socialista elegido constitucionalmente, lanza en la calle el potencial contrarevolucionario de su clientela femenina. Cuando escribía los dos primeros artículos, no sabía que la tragedia de un golpe de Estado iba a encargarse de darles su sentido exacto al articular esos textos sobre dicha perspectiva histórica, y a conferirles su significado político real. Y si insisto sobre este aspecto de mi experiencia, es porque precisamente estos trabajos me enseñaron la importancia política de la representación del género. Me afianzaron en la conciencia de la necesidad de atención sobre estos sistemas simbólicos, es decir, sobre las maneras que tienen las sociedades de servirse de la representación del género para articular las reglas de las relaciones sociales y para constituir el sentido de la experiencia.

En efecto sólo cuando por encima de las contradicciones de clase se organizó un movimiento de mujeres de derecha, se pudo calibrar, en medio del levantamiento, el peso específico de las inversiones políticas e ideológicas que día tras día la sociedad patriarcal había consolidado en el campo de los valores, de las normas de comportamiento, de las aspiraciones y sobre todo de las representaciones normativas del género femenino, a través de los medios de comunicación, entre otros. Representaciones normativas del género de las que, en tiempos de crisis, la oposición de los sectores conservadores iba a servirse.

Las manifestaciones callejeras "de las ollas vacías" revelaron, bajo una forma activa, los valores que los medios de comunicación tradicionales o modernos nunca habían dejado de cultivar bajo su forma pasiva. Demostraron en medio de la violencia cómo el carácter privado y pasivo, atribuido a lo femenino, ese carácter que las fotonovelas y las revistas habían acuñado en el discurrir de los días con ensoñaciones sobre aventuras de deseo amoroso o deseo de consumo, podía perder su aparente inercia pasiva dentro de la vida política para convertirse en un arma singularmente importante en las campañas de opinión contra un régimen popular constitucionalmente elegido y contra su programa de reformas.

Esas mujeres se transformaron en el mejor arma para el combate político, permitiendo vestir de inocencia a la subversión, presentándola como la reacción espontánea del sector tradicionalmente apolítico de la opinión, preocupado únicamente por asuntos domésticos y maternales. La prensa conservadora justificó el papel activo y sedicioso de las mujeres que se alinearon en las filas de la oposición, sirviéndose de la interiorización de los estereotipos femeninos, defendiendo que ese papel público que ellas ahora asumían no era más que una imagen temporal de la función privada y maternal que les asigna la naturaleza. Esta experiencia, lo repito, muestra la realidad profundamente política del sistema de representación del género².

Este tipo de análisis ponía de relieve el dinamismo del funcionamiento ideológico y de las condiciones sociales que producía esta disputa por el sentido de la "feminidad". La semiología había constituido un avance respecto al funcionalismo, pero conllevaba el peligro de la racionalización del funcionamiento interno de los textos. Lo que el proceso chileno enseñaba es que una ideología sólo lo es y funciona como tal en la medida que produce efectos políticos. Lo ideológico, entonces, se está pensando ya no solo como propiedad inmanente de las estructuras textuales, sino que se define en los efectos, en la lucha por la imposición de ciertos sentidos entre otros: la mujer asumía un papel de protagonismo político movilizando la olla, el símbolo de su opresión. Y este desplazamiento volvía inocente y despolitizado un interés de clase: nada más universal y natural que una madre movilizada por el pan de sus hijos.

A partir de la segunda mitad de los años 80, empezaron a publicarse estudios sobre recepción y audiencias. Fueron particularmente impulsados por la corriente de los Cultural Studies, llegando a representar la mayoría en el ámbito de análisis sobre "Género /Medios". Antes de reflexionar sobre esta orientación investigadora específica, hace falta subrayar la importancia del cambio de mirada que se produce en esa mitad de los años 80 en la Teoría Crítica de la comunicación. Después de aceptar la noción de "la masa de consumidores" como un objeto inerte y forzosamente manipulado, la Teoría Crítica tiende, a partir de ese momento, aun con matices internos, a suscribir el reconocimiento del estatus activo y productor de sentido del receptor-consumidor. Si hacemos memoria, en 1977 el movimiento de las mujeres demostraba ser muy activo en Francia. Una de sus pioneras escribió un artículo en la prensa alternativa sobre la necesidad de ir más allá de los análisis usuales de la "mujer objeto" y de aproximarse a las estrategias del desvío y la resistencia. Convencida de que algo estaba pasando en el lado de las consumidoras, una toma de conciencia, de palabra, de cuerpo, común, colectiva y plural, lo llamaba "la

\footnotetext{
2 Michèle Mattelart, La cultura de la opresion femenina, Era, Mexico, 1977 ; Mujeres e industrias culturales , Barcelona, Anagrama, 1982 ; « Mujeres y medios : memorias de un pensamiento critico, in M. J. Sanchez Leyva y A. Reigada Olaizola (coords), Sevilla :Comunicacion Social Ediciones, 2007.
} 
risa de las mujeres"3. Lo que se introducía, sí, era la noción de una posible distancia entre el modelo "mujer objeto" revelado por el análisis estructural de las revistas, programas de TV,etc... y el modo en que estaba percibido, recibido y vivido por las mismas mujeres en lucha. A la luz de este enfoque, se redefine el poder de la imagen. Se lo ve como un poder ejercido en un juego de vaivén que no funciona en el sentido exclusivo de la norma mediática. Un juego de vaivén en el que intervienen los sujetos atravesados por las significaciones atribuidas al género por el sistema de representación dominante en una formación discursiva dada. Pero en este juego, esos mismos sujetos intervienen también como actores socialmente situados que viven experiencias, tienen una práctica específica e interrelacionan, mediante el gesto y el lenguaje, la diferencia de los sexos y las relaciones de dominación. Lo que lleva a concebir el efecto de sentido como un proceso de negociación efectuado por un sujeto, en el espesor de su sociabilidad. Pero eso no autoriza a evacuar el poder de la imagen y de la representación sexista. Al connotar el "género femenino" con características especificas, los medios de comunicación constituyen unos agentes eficaces en la producción y la renovación constante de la "significación imaginaria" del sexo femenino. Significación imaginaria que produce efectos concretos en las diversas prácticas sociales.

El pensamiento de Michel Foucault contribuirá poderosamente a renovar la concepción del poder: "No se aplica, pura y simplemente, como una obligación o una prohibición, a los que no lo tienen ; los inviste, pasa por ellos y a través de ellos ; se apoya en ellos, al igual que ellos, en su lucha contra él, se apoyan a su vez en el dominio que él ejerce sobre ellos"4.

El movimiento feminista y la teoría crítica de la comunicación van cogidos de la mano en esa época donde se vuelven preponderantes las cuestiones de sentido y de sexualidad, mientras que, en el dominio político y económico, ese momento de los 80 , se caracteriza por la desregulación y la privatización de los medios, y en el dominio de las ideas, por el desarrollo de nuevas matrices conceptuales relacionadas en el contexto del post-estructuralismo y del post-modernismo, con la crisis de las utopías sociales, la crisis de las identidades y de los grandes relatos de emancipación.

Se produce, así, un cambio de paradigma en los estudios feministas sobre los medios. Desde las explicaciones deterministas de la subordinación de las mujeres por los media (entre otros factores) hacia los procesos de simbolización y de representación de los años 80 , el feminismo se volcó en la cultura, dejando de lado los modelos de la estructura social que daban cuenta de las relaciones de género, para volverse hacia cuestiones de sentido, de subjetividad. "Cuando la atención se desplaza de un análisis de las estructuras sociales y económicas hacia el modo en que la gente vive estas estructuras, a cómo producen sentido para ellos, a cómo se adaptan y a través de qué tácticas tratan de subvertirlas, la vida cotidiana se ve como el lugar donde se produce la articulación concreta de las estructuras. La vida cotidiana se ha vuelto la preocupación principal de la teoría cultural contemporánea y de la teoría feminista. En la investigación feminista sobre los media, este cambio de paradigma, en el seno del post-estructuralismo, ha producido nuevas cuestiones que no podían ser planteadas sino volviéndose hacia las audiencias» ${ }^{5}$.

El retorno a las audiencias va de hecho a transformarse en el nuevo paradigma. Y con él, un interés centrado sobre el contexto de la recepción 6 : la vida doméstica con sus ritmos, sus rutinas, las relaciones familiares y la distribución de los roles y de los poderes en el seno del espacio privado. En el campo de los estudios sobre televisión, surgió la necesidad de re-evaluar la mirada sobre los géneros del soap opera o de la telenovela. Despreciados por la crítica oficial, eran los géneros emblemáticos del interés de los publicitarios y de las agencias de marketing por esta misma razón: la dueña de la casa fue y es el eterno blanco de las estrategias comerciales ${ }^{7}$. Este interés por la recepción de estos géneros ha originado en varios círculos de investigación -relevando a los cultural studies alrededor del mundo- muchos estudios que se interesaron por la audiencia de una manera distinta de los "marketers": se trataba de utilizar estos textos como territorio para explorar la subjetividad femenina.

"Indudablemente, según expresa la investigadora argentina Maria C. Mata comentando esta preocupación por la recepción que se instaló a partir de mediados de los años 80 en América Latina ${ }^{8}$, hubo muchos aportes sociológicos, antropológicos y culturales que permitieron comprender el consumo de los medios como "conjunto de prácticas en las que se construyen significados y sentidos del vivir a través de la apropiación y usos de bienes"9. "En su mejor tradición -dice otro investigador- estos estudios han hecho aportes realmente importantes para un conocimiento mejor de la sociedad"10.

${ }^{3}$ Liliane Kandel, « Face à Femmes » primer numero de la Revue Alternatives, Paris, 1977.

${ }^{4}$ Michel Foucault, Surveiller et punir, Paris, Gallimard, 1975(trad.cast : Vigilar y castigar, Siglo XXI, 2000 ).

${ }^{5}$ Michèle Barrett ,ideology and the cultural production of gender ,London, Verso,1989.

${ }^{6}$ Debo decir que trabajé temprano sobre el concepto de vida cotidiana para analizar la relacion de las mujeres con los géneros « femeninos ». El concepto de « trabajo invisible » fue clave en este análisis. El movimiento feminista internacional trabajó mucho sobre este concepto en los años 70 . Denunciaba el valor negativo atribuido al trabajo doméstico de las mujeres, devaluado, sin retribución económica.(Es un concepto que sigue movilizando el movimiento feminista). Esta invisibilidad del trabajo doméstico, el ocultamiento de su valor productivo son de una importancia decisiva para determinar la imagen de las mujeres y la relación de los media con ellas. Esta división del trabajo ilustra de modo ejemplar la discriminación entre la esfera privada y la esfera pública, entre el espacio de la producción y el espacio de la reproducción, con los estatus sociales y simbólicos que les son respectivamente atribuidos. Cf La cultura de la opresión femenina, op.cit.

${ }^{7}$ Aunque recientemente estas estrategias comerciales se volcaron también hacia los niños/as, los/las adolescentes y los hombres.

${ }^{8}$ En América Latina, se desarrolla a partir de ese momento una corriente de « estudios culturales » con sus rasgos específicos. Sus figuras emblemáticas son J-M. Barbero y N. Garcia Canclini. Suscitaron interrogantes sobre la articulación entre las culturas populares y la producción industrializada de la cultura y sobre la recepción del género telenovela, así como sobre los complejos procesos de apropiación de los flujos de la modernidad global.

${ }^{9}$ Maria C. Mata in H.Schmucler y M.C.Mata (coords), Politica y Comunicacion. Hay un lugar para la política en la cultura mediática?

Catálogos, Buenos-Aires, 1992.

10 Hector Schmucler, idem. 
Pero se ha podido observar últimamente una inquietud frente a la significación de la hegemonía de las teorías de la recepción y del auge de la mirada desde lo cultural ${ }^{11}$. Inquietud expresada por los dos investigadores que acabo de citar: "La idea de lo cultural que culturiza todas las prácticas sociales, entre otras la comunicación, se ha instalado, relegando lo político-estructural (la aversión por todo lo que es estructural) a un plano secundario....Ha llegado un momento en el cual hablar del poder de los medios, hablar de la función orgánica de los medios en relación con el modelo social, se ha puesto muy difícil. Se ha instalado la idea, ligera, fácil, de que nada es malo, de que todo está bien y de que todo se puede utilizar. No se trata de hacer marcha atrás, pero sí de recuperar esta organicidad entre las formas de la expresión cultural, entre la comunicación y los modelos generales de tipo económico y social"12.

El postulado de un receptor/a "resistente" al cual se adhirió cada vez mas esa corriente, se vio bastante rápidamente acusado de banalizar el concepto de resistencia y de diluirlo. Las mismas pioneras emblemáticas de la misma reconocen que quienes "consideran que la valorización de las capacidades de resistencia del telespectador asume hoy en día rasgos de deriva populista" ( len Ang, 1991) ${ }^{13}$. Mientras que Janice Radway ${ }^{14}$, otra autora reconocida, expresa escepticismo sobre su alcance: "A propósito de la esfera del ocio, del tiempo libre, necesitamos saber si las pequeñas victorias logradas ahí, buscando el poder, pueden ser trasladadas a otras esferas y fundadas como la base de una respuesta más amplia al orden social dominante".

Planteamos tempranamente (en 1973), durante el gobierno de la Unidad Popular, con una investigadora argentina exiliada en Chile, Mabel Piccini, un estudio en torno a la recepción, distinto a como se planteo la problemática años mas tarde. Lo distintivo era la clave en la que ésta era abordada. La recepción era un proyecto. Criticando la noción de pasividad de la audiencia, nuestro estudio se inscribía en torno a cómo los sectores populares, hombres y mujeres, resistían y creaban alternativas políticas y culturales en el marco de un proceso de transformación radical. La finalidad de nuestra intervención era discutir el estatuto "universal" de la audiencia (la propia noción de "masa") y dar cuenta, por el contrario, de su productividad a partir de su conciencia política. El blanco de la crítica eran las políticas comunicacionales de los partidos de la Unidad Popular, cuya estrategia había impuesto sucesivos controles a la participación y al poder popular en todos los frentes y en particular en el frente cultural. En este sentido, a partir de la recuperación de la dimensión productiva del receptor y de la receptora, nos proponíamos, en contraposición a esa política, construir canales de mediación entre los productores y los sectores populares, canales que tenderían a que estos se transformaran en sujetos activos de una experiencia cultural15.

Como se ve, este último párrafo sobre los sectores populares incluye a hombres y a mujeres en la perspectiva de los procesos de emancipación. El hecho de terminar esta presentación evocando dicho estudio polifónico que se interesó tanto en la recuperación de la dimensión productiva de la receptora mujer como del receptor hombre, me hace pensar en el final de un libro colectivo sobre los derechos de la mujer en el que Françoise Collin escribía: "El derecho debe a la vez conceder un lugar a la diferencia sexual sin por eso encerrar las mujeres en su sexo: "yo soy una mujer, pero Yo no es una mujer". Y es porque las mujeres no pueden ser encerradas en su sexo por lo que toda mejora de la defensa de sus derechos representa necesariamente una mejora de los derechos de la persona humana".

\footnotetext{
${ }^{11}$ No podemos sino recordar a propósito de esta preocupación sobre el auge de la mirada desde lo cultural, el pensamiento de Nancy Frazer, que lo atribuye al contexto del post- socialismo, y le opone reivindicaciones desde el concepto de re-distribución. 12 Hector Schmucler, idem

${ }^{13}$ len Ang, Watching Dallas : Soap opera and the melodramatic imagination » Routledge, London , 1985 y Desperately Seeking the audiences, Routledge, London, 1991.

14 Janice Radway, Reading the romance, Women, patriarchy and popular literature, University of North Carolina Press, 1984 y 1991.

${ }^{15}$ Michèle Mattelart y Mabel Piccini, « La televisión y los sectores populares », Comunicación y cultura n 4, Buenos-Aires- Mexico, 1974.
} 